\title{
Power System in Center and Southern Albania: Paving the Problem of Flow Distribution of Power in the Power System
}

\section{Pranvera Hysenaj}

\author{
Phd Candidate, Department of Electrical Engineering, Albanian University, Tirane ,Albania \\ Email: pranvera_cako@yahoo.com
}

\section{Doi:10.5901/ajis.2015.v4n2s2p130}

\section{Abstract}

\begin{abstract}
The purpose of this study is to analyze the distribution of power flows on the power system, considering that the main energy sources are located in the northern part of the country. The most important users of it are in central and South Albania, where almost absent generating sources and reactive power compensation. To make a detailed analysis of the current situation of the transmission system in our country are exploiting SEE scheme for program distribution power flows. Received the results from the execution of the Distribution Program power flows to the region of Tirana,Durres, Elbasan and the southern part of the system.
\end{abstract}

Keywords: The power system, active power, reactive power, electrical loads, the mathematical model equations.

\section{Introduction}

Albania has a Power System based mainly on water resources repeal. It realizes the export of electricity mainly in the winter with neighboring systems, (former Yugoslavia and Greece) where generation in these systems mainly based on plants. The possibilities of exchange and marketing of electricity between Albania and its neighbors, based on the peculiar and respective features of these systems. Cargo performance shows that in recent years the demand for electricity has grown significantly and together with the peak load.

In the period of maximum load of the power system Albanian winter often are struggling to preserve the balance of reactive power. In this period of one big influx jet enters our system through the Greek system $400 \mathrm{kV}$ interconnection line. Maintaining the balance of reactive power (Pai 1989; Miller1982) is one of the fundamental requirements to work in parallel with regional . In particular, active power produced is used to cover the requirements for active power losses and active users on the network. To judge the fulfillment of these is enough to be taken as a criterion of the system working frequency of which should be $50 \mathrm{~Hz}$ in a normal state. And reactive power produced by the system, so the generators, high voltage lines, etc, serves to meet the demand for reactive power losses and reactive users on the network. As a criterion for its fulfillment serving sizes tension values at different points of electric network.( Jayaram and Salama 2000)

\section{Material and methods}

Graphic materials are used and the following data: A topographic map that shows the extent of transmission lines of 400 $\mathrm{kV}, 220 \mathrm{kV}, 110 \mathrm{kV}$ and $35 \mathrm{kV}$.

Principal scheme of $400 \mathrm{kV}$ transmission system, $220 \mathrm{kV}, 110 \mathrm{kV}, 35 \mathrm{kV}$ together with the identification of all the different nodes System. A series of documents OST to provide full data and detailed equipment system features shown in the principal scheme. New schemes to date regions of Tirana, Durres, Elbasan and scheme southern region of our country. Characteristics of generators, transformers and transmission line.

\section{Data collection}

The basic information to assess the state of the electric grid (Bergen; Vittal 2000) of the system are direct measurements in the system (for the period of 2014), the sizes of loads on the joints, working regimes and powers of production units (except node balancing) and network configuration.(.Kurita;.Sukurai 1988) Electrical quantities measurements carried out in the system are always associated with errors (Haque; Yam 2003) as a result of the apparatus, broadcasting for measurement wrong, not linearity (Domel 1969). 


\section{Data analysis}

Using the mathematical model to assess the situation (Billinton; Ringlee;Wood 1973 ) assume that the electric network are carried $\mathrm{M}>2 \mathrm{~N}-1$ measurement of electrical sizes. Wi marked with electric size of which is measured in the system and each of them based on network mathematical model written an algebraic equation:

\section{Wi $=$ fi $(X)$}

Errors "know" the measurement determined

di $=-$ Wi $=$ WMI WMI - fi $(X)$ minimizes the sum of squares of errors.

$\sum d_{i}^{2}=\Sigma\left[W_{m i}-f i(X)\right]^{2}=\min$

Xop solution found by a tie at zero partial derivatives of the first order

$(\partial \mathrm{d} / \partial \mathrm{X}) \mathrm{T}^{*} \mathrm{~d}=0$

expression $\partial d / \partial X$ is a matrix with dimensions $M * 2 N-1$ and called Jakobiani the system. (Muller ;Sverak 1996)

$$
\frac{\partial d}{\partial X}=J=\frac{\partial f_{1}}{\partial X_{1}} \ldots \ldots .
$$

The system is non-linear equations ${ }^{(11)}$, and the solution is iterative methods based on it.In linearity matrix form:

\section{$F(X)=W_{0}+J_{0} X$}

$W 0$ and $J_{0}$ are respectively the vector $W$ and Jakobiani, estimated at point $X_{0}$

$$
\mathrm{X}=\left(\mathrm{J}_{0}^{\top} \mathrm{D} \mathrm{J}_{0}\right)^{-1} * \mathrm{~J}_{0}^{\top} \mathrm{D}\left(\mathrm{W}_{\mathrm{M}}-\mathrm{W}_{0}\right)
$$

Expression (7) is the basic expression of iterative process, which allows to move from a starting point to another point until reaching the system solution. In the second case the minimum number of measurements is possible $\mathrm{M}=2 \mathrm{~N}$ 1. To find a solution to the error vector $d$ is equal to zero.

$F(X)=W M$

Jakobiani I system is a square matrix of dimension $(2 \mathrm{~N}-1) *(2 \mathrm{~N}-1)$.

$X=J_{0}-1 D_{0}^{-1}\left(J_{0}^{\top}\right)^{-1} * J_{0}^{\top} D * W=J_{0}^{-1} D^{-1} D W$

finally:

$\mathrm{X}=\mathrm{J}^{-1} \mathbf{W}$

Formula (9) it is the basis for Newton-Rafson iterative method

\section{Outcome}

Measurements of power lines are the most useful measurements and are used by the assessment of the situation. (Dedei;Bualoti 1997).

The graph shows a part of the electric grid with three joints and two lines which are measured all electric powers:

$\mathbf{S i j}, \mathbf{S j}, \mathbf{S k}$ - $\quad$ they are powers of i, j and $\mathrm{k}$.

Sij, Sji - are powers that go in line ij powers at the beginning and end of line Sik, Ski - have powers to take off line.

In measuring: $\mathrm{S}=\mathrm{P}+\mathrm{jQ}$ 


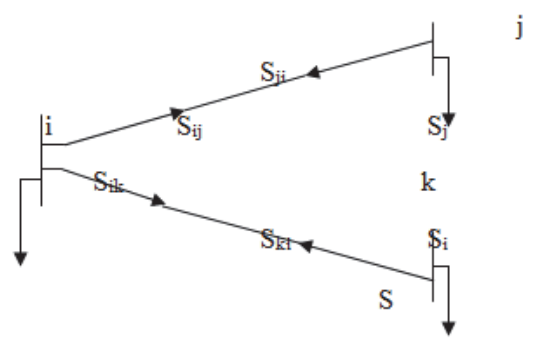

Figure 1. Schematic representation of some measurements on the electrical network

For node "i" is written equations for active power and reactive power. In this case formed a single measurement of power as a linear combination of the measurements performed.

$$
\begin{aligned}
& P_{k m i}=P_{i}+P_{i j}-P_{j i}+P_{i k}-P_{k i} \\
& Q_{k m i}=Q_{i}+Q_{i j}-Q_{j i}+Q_{i k}-Q_{k i}
\end{aligned}
$$

If it is marked with a final row vector:
$a_{i}=\mid 1$
0
0
1
$-1 \quad 1$
$\left.\begin{array}{l}1 \\ M\end{array}=7\right)$
$\left|\begin{array}{lllllll}\mathbf{W}_{\mathrm{p}}^{\top}=\mid \mathbf{P}_{\mathrm{i}} & \mathbf{P}_{\mathrm{j}}, & \mathbf{P}_{\mathrm{k}} & \mathbf{P}_{\mathrm{ij}} & \mathbf{P}_{\mathrm{ji}} & \mathbf{P}_{\mathrm{ik}} & \mathbf{P}_{\mathrm{ki}} \\ \mathbf{W}_{\mathrm{q}}^{\top}=\mid \mathbf{Q}_{\mathrm{i}} & \mathbf{Q}_{\mathrm{j}} & \mathbf{Q}_{\mathrm{k}} & \mathbf{Q}_{\mathrm{ij}} & \mathbf{Q}_{\mathrm{ji}} & \mathbf{Q}_{\mathrm{ik}} & \mathbf{Q}_{\mathrm{ki}}\end{array}\right|$

$\left|\begin{array}{lllllll}W_{p}^{\top}=\mid P_{i} & P_{j}, & P_{k} & P_{i j} & P_{j i} & P_{i k} & P_{k i} \\ W_{q}^{\top}=\mid Q_{i} & Q_{j} & Q_{k} & Q_{i j} & Q_{j i} & Q_{i k} & Q_{k i}\end{array}\right|$

$\mathbf{P}_{\mathrm{kmi}}=\mathrm{a}_{\mathrm{i}} \mathbf{W}_{\mathrm{p}}$

$\mathbf{Q}_{\mathrm{kmi}}=\mathbf{a}_{\mathrm{i}} \mathbf{W}_{\mathrm{q}}$

W k M denote the combined measurement vector length $2 \mathrm{~N}-1$, the A matrix formed by rows it.

$\mathbf{W}_{\mathrm{kM}}=\mathbf{A} \mathbf{W}$

A matrix having dimensions $(2 \mathrm{~N}-1){ }^{*} \mathrm{M}$ is called the incidence matrix and its elements are:

$\mathbf{a}_{\mathrm{ij}}=\mid 0$ when measuring the $\mathrm{j}$ th equation does not affect the $\mathrm{i}$-node

1 when measuring the j-enters the equations of the intersection of I-to the mark +

-1 When measuring the j-enters the equation of I-node of the sign -

Combined form under (13) has better results in the assessment of the electric grid in determining the distribution of power flows. (Dedei;Bualoti 1997)

Skmi $=$ Si

(15)

Equation (14) is now presented in the form of nonlinear algebraic equations system for elements $\mathrm{W}$.

WKM $=A F(X)$

$2 \mathrm{~N}-1$ system of nonlinear algebraic equations constitute mathematical model generalised distribution of power flows on the electric network.

\section{Discussion}

- Creation of new resources in the central and southern part of the country .The strengthening transmission( Domel 1969; .Angles and Chamacho 2008) system 220/110 kV through the construction of new lines and transformer substations 220/110/20 kV.

- In SEE circulates a large reactive power. No availability of aggregates to cover reactive power(Moghavvemi;Faruque 1998) required due to very large losses in transformers, auto-transformers, 220KV lines

- Interference in transmission by means of compensating in the southern part of the system. (Gao;Morison.and Kundur 1992)

\section{Conclusion}

Measurements carried out in the system by use of computers in center dispatcher realize real-time control of the power system. Estimation of the situation becomes relying on mathematical model for calculating the distribution of flows. Number of measurements always system is greater than the number of unknowns. The state's electric grid system called 
known when exactly recognized acceptable voltage values modules in network nodes as well as active power flows in all its lines and transformers.

Using method Newton-Rafson and nonlinear algebraic mathematical model for estimating the distribution of flows assume that the electric network with $\mathrm{N}$-node power system measurements are performed sizes $\mathrm{M}$ electricity.

When the minimum number of measurements is therefore a potential $\mathrm{M}=2 \mathrm{~N}-1$. We find the solution of equations use mathematical model with the assumption that the error vector $\mathbf{d}$ is equal to zero. The measurements are accurate. $\mathrm{M}=$ $2 \mathrm{~N}-1$ system of nonlinear algebraic equations formed represent mathematical model generalized distribution of power flows on the electric network.

When the number of measurements is $\mathrm{M}>2 \mathrm{~N}-1$. We find a solution to use mathematical model equations and nonlinear optimization problem as a problem arises, is the vector of state variables Xop which minimizes the error vector $\mathbf{d}$ measurements. The measurements are inaccurate and carried out a series of calculations. The measurements add up to solve the problem. Given the fact that various measures have different errors and confidence in the accuracy of measurements is different. In these equations set in each measurement coefficient Ki gravity (weight). These coefficient penalize those measurements which are less accurate. Using mathematical method not linare algebraic equations for $2 \mathrm{~N}$ 1 measurement of active and reactive power generalized to determine the distribution of power flows on the electric gri When the number of measurements is $\mathrm{M}>2 \mathrm{~N}-1$ use mathematical model of nonlinear equations. The problem arises as the optimization problem. Available vector of state variables Xop which minimizes the error vector measurement $d$. Measurements are inaccurate. They carried out a series of calculations and measurements to solve this problem. In these equations set in each measurement coefficient Ki relevance to eliminate those measures which are less accurate.

\section{References}

M.A .Pai " Energy Function Analysis for Power System Stability “ Kluwer Academic Publishers ,Norwell. MA 1989 page $222-227$ T.J.E.Miller "Reactive Power Control in Electric System" New York MCGraw-Hill 1982 page 169-171

Kannan S. Jayaram S. Salama M “ Real and Reactive Power Coordination for a Unified System” 2000 page 62-257

Bergen .A.R.and Vittal V "Power System Analysis “ New Jersey 2000 page 388-399

A.Kurita .T.Sukurai "The Power System " Tokyo 1988 Proc.Of the 27-th Conference on Decision and Controll.

Haque MH .Yam CM "A Simple Method of Solving the Controlled Load Flow Problem of Power System" Electric Power System Research 2003 page 55-62

M.Larson .C.Rehtanz . J.Bertsch "Monitoring and Operation Transmition Corridors " in I Power Tech Conference Proceedings June 2003 vol 3

Domel .H.M "Digital Computer Solution for Transaction on Power Apparatures and System " The MIT Press 1969 vol 4

R. Billinton, R. Ringlee, A. Wood, "Power System Reliability Calculations", The MIT Press, Cambridge, Mass.1973 ,page1-220.

S.Muller V.Sverak "Geometric Analysis and Calculus of Variations "Internat .Press Cambridge 1996 page 239-251

T.F.Halpin . R.Fischel .R.Fink "Analysis of Automatic Contingency Selection Algorithms "Springer-Verlang Germany 1984 page $938-$ 945

A.Dedei.R.Bualoti. “"Transitional Processes Power System 1" Publishing "University Book"...Tirane .1997 (reprint)

Domel .H.M "Digital Computer Solution for Transaction on Power Apparatures and System " The MIT Press 1969 vol 4

F.Angles H.Chamacho "An Open Source Power System Analysis Toolbox" Fact Press Italy 2008 vol3 page 199-206.

D.C .Elizando . S.Horowitz . A.G.Phadke "Hiden Failures in protection system and their Impact on Wide Area Disturbances " in Proc of the conference on Power Engineering Socity Winter Meeting 2001 vol 2 page 710-714

M.Moghavvemi. O.Faruque ."Real-Time Contingency Evalutation and Ranking Technique" Forida CRC Press 1998 vol 5 page 145.

Michalin R . .Zunko P . .Povh D. "Impovement of Transient Stability Using Unified Power Controller" New York John Wiley and Sons 1996 page $92-485$

B.Gao.G.K.Morison.and P.Kundur. "Voltage stability evalutation using Modal Analysis "Transaction on Power System " New Jersey 1992 .vol 7 .page 529-542. 